\title{
Analysis of Maize Commercialization Among Smallholder Farmers: In the Case of Gog Districts, Anywaa Zone, Ethiopia
}

\author{
Anuto David Ojulu \\ Department of Agricultural Economics, Gambella University, Gambella, Ethiopia
}

\begin{abstract}
Agricultural commercialization is a process of transformation from subsistence farming system to market oriented production system. Motivating smallholder farmers to produce further than their consumption and empowering them to be profit oriented should be given priority in order to foster the economic growth in developing countries where agriculture is the pillar of the economy and smallholder farmers are the largest section of the country like Ethiopia. Nevertheless, due to a number of reasons smallholder farmers' level of commercialization is very low and insignificant. There are only few studies conducted about agricultural commercialization in Ethiopia but the studies are not focused to the study area. Consequently, the aimed to analyze the factors that determine market participation and degree of commercialization by smallholder maize producers in Gog district, Anywaa Zone, Ethiopia. Data were collected from 385 smallholder maize producers in three districts where maize is produced potentially through multistage sampling method. Furthermore, interview schedule, focus group discussion and key informant interview were used to gather the required primary data. In order to attain the study aims, Tobit model was employed to analyses both market participation and intensity of commercialization. From the analysis education level, livestock holding, frequency of extension contact, training, off/non-farm income activity, quantity of maize and lagged price were found to have significant effect on market participation while intensity of commercialization was significantly influenced by education level, livestock holding, training, frequency of extension contact, off/non-farm activity, quantity of maize produced and lagged price. To conclude based on the results, smallholder maize producers should be supported frequently by extension agents in order to upsurge their practical skills which results enhancement of their market participation and intensity of commercialization.
\end{abstract}

Keywords: Gog, Commercialization, Maize, Smallholder producers, Tobit model

DOI: $10.7176 / \mathrm{JESD} / 12-21-03$

Publication date: November $30^{\text {th }} 2021$

\subsection{Introductions of the study}

Agriculture is the mainstay of Ethiopian economy as it is a means of livelihood for about $84 \%$ of the population and it constitutes about $33.3 \%$ of the country's GDP (NBE, 2018). The majority of farmers in Ethiopia are smallholders and they are a source of $95 \%$ of the country's agricultural production (CSA, 2018). Enhancing the productivity of smallholder farmers has been the primary goal of the government in order to foster the economic growth in Ethiopia.

Despite the circumstance that agriculture is presenting a remarkable progress in Ethiopia, it is not yet advanced to the expected level. Therefore, Low productivity, low employment of agricultural technologies and subsistence-based smallholder farming are still the characteristics of the sector (Doss et al., 2003; Shita et al., (2018). On the others way, strategies and policies designed to bring economic growth in the country such as Agriculture Development Led Industrialization and Growth and Transformation Plan has been mainly focusing on agricultural development through shifting the current smallholder subsistence based farming to commercialized agriculture (Gebreselassie, 2006; MoFED,2006). Furthermore, Agricultural commercialization is a process of transformation from subsistence farming system to market oriented production system (Alemu et al., 2006). Commercialization in smallholder farming is very important for low income countries since it has a potential to improve incomes and play a key role in reducing rural poverty level (Awotide et al., 2016; Hailu et al., 2015; Osmani et al., 2014). Agricultural commercialization particularly grain crops are more subsistence than cash crops in Ethiopia. Ethiopian low level of commercialization can be explained by, market imperfections, lack of capital, lack of market accessibility and high transaction costs (Getahun, 2020; Hagos \& Geta, 2016; Senbeta, 2018).

There are several studies conduct in Ethiopia on the different commodities by different researchers. For instant (Abafita et al., 2016; Abadi, 2014; Getahun, 2020; Hailu et al., 2015; Agerie, et al., 2017), they identified the factors affecting the commercialization of the crops and their participations. Despite to this, there was no any study being conduct in the study particularly in Gog district, Anywaa zone, Gambella, Ethiopia.

\subsection{Methodology of The Study}

A combination of different sampling procedures was used to select the samples to successfully meet the aims of the study. The sampling frame of the study was the list of households in the selected kebeles, in the respective districts of Gog districts, who are engaged in maize production. Households are the unit of analysis. A multistage sampling procedure was employed to select potential maize producer farmers. In the first stage, Gog districts were 
selected purposively based on their maize production potential. In the second stage from the selected districts, six maize producing kebele were selected using simple random sampling technique. In the third stage, households in the selected kebelles were stratified in to maize producers and non-producers. Finally, 385 smallholder maize farmers were selected using systematic random sampling technique by taking in to account the proportion of number of maize producers in each kebelle in the corresponding districts. To obtain a representative sample size, for cross-sectional household survey the study employed the sample size determination formula given by Kothari (2004):

\subsection{Sources of data and methods of collections}

Both primary and secondary sources of data were used. Before the data collection, the questionnaire was pre-tested on selected farmers to evaluate the appropriateness of the design, clarity, and relevance of the questions. Having the appropriate modification on the questionnaire based on the pre-tested result three enumerators from each districts were recruited and trained about the content of the questionnaire and interviewing process. Primary data were collected using interview schedule, focus group discussion and key informant interview whereas secondary data were also collected to supplement the primary data from published and unpublished sources.

\subsection{Method of Data Analysis}

Two types of analysis, namely: descriptive and econometric analyses were used for analyzing the data. Descriptive method of data analysis refers to the use of ratios, percentages and means in the process of examining and describing household characteristics. To analyses the factors that determine market participation and intensity of commercialization Tobit model was employed. Intensity of commercialization was measured as the ratio of the percentage of marketed output to total production. It is necessary to show the decision of smallholder maize farmers' market participation in order to estimate the degree of commercialization.

The dependent variable, decision to commercialize and intensity of commercialization, in this case has an upper limit of one in all cases and a lower limit of zero. The rationale for this is to match farmers' decision to fit the Tobit model that cannot take dependent variables greater than one or a negative.

\section{Results and Discussion}

\subsection{Socio-Economic Characteristics of Respondents}

Sample respondents were composed of both female and male household heads. Accordingly, about 5\% were female headed households and about $95 \%$ were male headed households. In terms of participation in maize market, $24 \%$ of household heads were participant while $76 \%$ of the households were not participant. The average age of the respondent households were 46 years with a range minimum of 25 years and maximum of 76 years. Similarly, the average quantity of maize annually produced was 15.27 quintal while the minimum was one Quintal and 54 quintals was the maximum. The average amount of maize supplied to market was 3.52 quintal and the minimum was supplied nothing and the maximum was 35 quintals. The extent of maize commercialization was $23 \%$.

Table 1. maize production and marketing related problems identified by the sample respondents

\begin{tabular}{|l|l|l|}
\hline s/no & Problems identified by respondent & percent \\
\hline 1 & Lack of improved maize seeds & 45.5 \\
\hline 2 & Poor road infrastructures & 41 \\
\hline 3 & Low prices & 33 \\
\hline 4 & Weathers changes & 49 \\
\hline 5 & Inadequate transportation service & 70.23 \\
\hline 6 & Lack of the input supply & 45 \\
\hline
\end{tabular}

Source; Field study 2020.

Table 1. Discloses on production and marketing problems of maize in the study area. As observed from the table, $95.53 \%$ of the households reported that lack of improved maize seeds as serious problem for maize production in the study area. maize disease is another major problem in the study area according to the percentage response of the households $(58 \%)$.

They criticize that, American worms in particular destroying their maize on farm thereby contributing low harvest of output. Additionally, binding constraint in production and marketing of maize in the study area reported by sample households is lacks of input supply. As result, $50.67 \%$ of the households responded as they were suffering from lacks of input supply. According to their response, as volatility in market prices of fertilizer, improved seeds and labor highly discouraging them are discouraging at the district. A relatively low market price of maize was also among production and marketing problems reported by about $49.33 \%$ of the households.

Poor road infrastructure, inadequate means of transportation, and weather change were also identified as constraints in maize production and marketing in the study area by $46.67 \%, 20.67 \%$, and $31.33 \%$ sampled respondents respectively. According to respondents, poorly developed road infrastructure in the area made them face difficulty in transporting their output and incur significant transportation cost. In this regard this study is in 
line with study conducted by Firdisa (2016) who also demonstrated that poor infrastructure being one of major problems of crop production of rural areas. Also, there is poor facility in public means of transportation. Inadequate public means of transportation could be associated with poor road infrastructure both of which force farmers sell their produce at farm gate price. Weather change was also reported as a critical problem in production of wheat in the study area. Rendering to respondents, variability in rainfall occurring at time of sowing and harvesting was highly reducing their production potential due to deterioration of yields.

\subsection{Determinants of Market Participation and Degree of Commercialization}

As already mentioned in the methodology section, this study employed Tobit model to estimate both determinants of smallholder maize producers' market participation and intensity of commercialization. Commercialization index which is a ratio of quantity of maize supplied to market by a particular household in the specified year to the quantity of maize produced by the same household in the same year was used to measure the intensity of maize commercialization (Abafita et al., 2016; Makombe et al., 2017). Results of the Tobit model revealed that seven variables were found to be significantly creating variation on the probability of smallholder maize producers' market participation and degree of commercialization out of the total thirteen explanatory variables.

Education level, livestock holding, Frequency of extension contact, Training, Off/non-farm income activity, Quantity of maize, lagged price were explanatory variables significantly influence probability of smallholder maize producers market participation and degree of commercialization. Overall, the probability of smallholder maize producers to sell their maize in the output markets was $76.3 \%$. Tobit estimation for maize commercialization is presented in Table 1 and statistically significant explanatory variables are interpreted as follows:

Education level: the variable education level is a continuous variable measured a grade of formal schooling which had positively influence the probability of market participation and degree of commercialization of maize at $1 \%$ level of significance. This indicates that household who were more educated had better market participation and high degree of commercialization. The positive relationship could be due to the fact that educated people can more easily contribute to the generation of new technologies and more readily utilize those technologies (Derso et al., 2016). Furthermore, educated people manage their fields properly and then this activity results have pushes to get good production and productivity of the land. This result is in line with the findings of Awotide et al., (2016) which is analyzed by Heckman two stage model and confirmed that level of education has positive and statistically significant effect on market participation of farmers in rice marketing.

Frequency of extension contact: It is obvious that agricultural extension services play a vital role in motivating farmers towards accepting and implementing improved agricultural technologies and agronomic practices. However, the result of this study shows that frequency of extension contact negatively and significantly influence the probability of maize market participation and degree of commercialization at $5 \%$ level of significance. This might be smallholder maize producers who have frequent contact with development agent could not get practical information on new technologies and agronomic practices which might boost their production and productivity of maize. Instead development agents out of their profession, might spent their time with farmers talking about politics and other issues which is not directly relevant to enhance farmers' production and productivity.

Negative but statistically significant effect of extension service on market participation and commercialization level had been reported in some other African countries such as in rural Nigeria (Awotide et al., 2016) and in Ghana (Martey et al., 2012).

Training: training was found to have positive and statistically significant influence on both the probability of maize market participation and degree of commercialization at 5\% significance level. Thus, Trainings on application of new agricultural technologies, agronomic practices, harvest and post-harvest loss minimization and other related trainings could build smallholder farmers' production capacity. Ultimately, it increases the likelihood of maize market participation and degree of commercialization for producers. In line with our finding a study conducted in the northern part of Ethiopia, Tigray Region, confirmed that training on crop marketing has a positive and significant effect on intensity of crop commercialization (Hailu et al., 2015).

Off/non-farm income activity: This variable was measured in terms of whether or not respondents get additional income from off/non- farm income beyond their own agricultural activity. Off/non-farm income activity had positively and statistically significant influence at $1 \%$ level of significance on the probability of market participation and degree of commercialization. The positive relationship could be because of farmers who have got additional income from off/non-farm activities might not face financial shortage to purchase farm inputs to increase their maize production and productivity which ultimately increases their market participation and degree of commercialization. This result was in line with the findings of Hailu et al., (2015) which states that off-farm income is the driving force of increased crop commercialization. In addition, Matthews et al.,(2015) confirmed that the direct effect of off/non-farm income in enabling smallholder farmers to be technical efficient in maize farming in Ethiopia. This might increase the production level and market participation of the farmers. Contradicting to this result, off/non-farm income had shown significant negative influence on farmers' market 
participation was reported by Awotide et al., (2016) and commercialization level by (Martey et al., 2012).

Livestock holding: this variable was a continuous variable measured in Tropical Livestock Unit (TLU) was found to have negatively and statistically significant at $10 \%$ level of significance on the probability of smallholder maize producer market participation as well as degree of commercialization.

The negative relationship could imply that as the households' have more livestock endowment, their market participation and degree of commercialization decreases. The possible reason might be to purchase farm inputs which can enhance production and productivity like fertilizer, improved seed, pesticides and insecticides, farmers directly sell their livestock and store their maize output. This finding contradicts with the findings of Abafita et al., (2016). In their study on smallholder cereal farmers' commercialization in Ethiopia by using Heckman two stage models, Ox that is a proxy for total livestock holding had positive effect on probability of participation on cereal marketing.

Quantity of maize produced (in quintal) this variable was found to have positive and statistically significant influence on the probability of participation in maize marketing as well as degree of commercialization at 5\% level of significance. As the evidence obtained from sample respondents, maize producers who produced more had better chance to participate in maize marketing and supply high amount of maize in to the market. A previous study conducted in Ethiopia has shown a significant positive effect of value of crop produced on the probability of market participation and the level of commercialization by smallholder cereal farmers (Abafita et al., 2016). In addition, the study conducted in rural Nigeria confirmed our result and it indicates that the positive and statistically significant effect of yield of rice on farmers' riJTGVR5YEL; Kce market participation and welfare maximization (Awotide et al., 2016).

Lagged price: which was measured in Ethiopian birr had positive and statistically significant relationship with probability of maize market participation and degree of commercialization at $1 \%$ level of significance. This research finding is in line with the study by Martey et al., (2012) conducted in Ghana founded the significant effect of unit of price output on intensity of commercialization was documented in the study by. Therefore, it was due to the fact that lagged price of maize was high. Accordingly, as High price level of the output in the previous year was higher it could motivate maize smallholder farmers to produce more in the form of allocating more land and use of appropriate agricultural technologies and to increase their market participation and degree of commercialization.

Table 2. Determinants of Market Participation and Degree of Commercialization

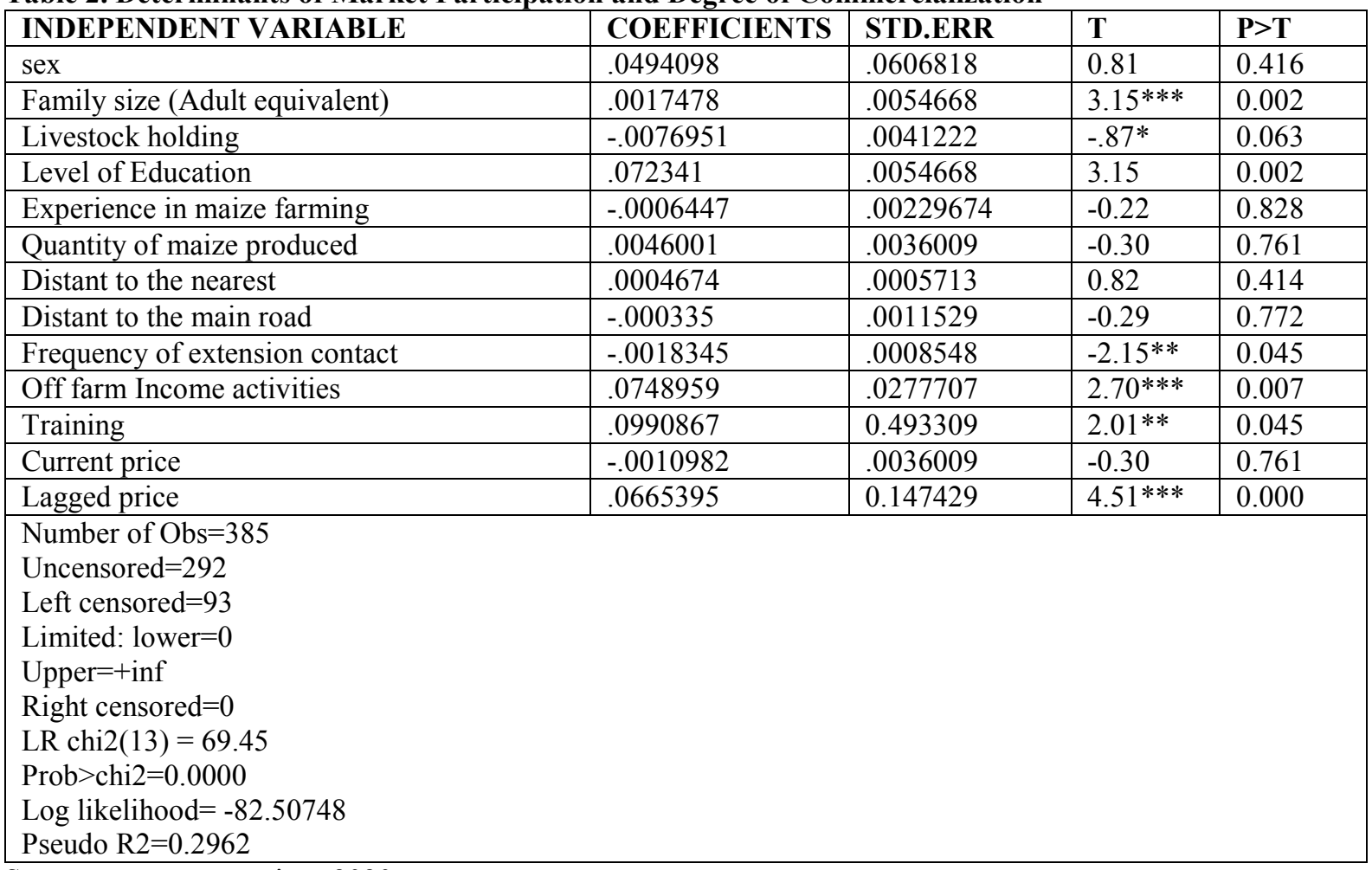

Source; own computations 2020

Note: $* * * * *$ and $*$ represents significance level at $1 \%, 5 \%$ and $10 \%$, respectively

Effects of changes in significant explanatory variables

All variables that were found to influence the participation decision and degree of commercialization might not 
have similar contribution for influencing the participation decision and degree of maize commercialization. Hence, using a decomposition procedure suggested by (Moffitt \& Mcdonald, 1980), the marginal effect results of Tobit model was used to assess the effects of changes in the explanatory variables into participation decision and intensity as follows by using the decomposition command which is dtobit2. The dtobit 2 command estimates a Tobit model and provides a table of marginal effects evaluated at the observed censoring rate of the dependent variable. The marginal effects were computed for the dependent variable conditional on the censoring and on the unconditional expected value of the dependent variable. Therefore, the effects of each significant explanatory variable which affects smallholder maize producers' probability of maize market participation and degree of commercialization is interpreted as follows based on the marginal effect results presented in Table 1.

Education level: Educated members are expected to have more exposure to the external environment and familiar with their duties and rights they have in different social activities and need to actively participate in economic and democratic right to take right decision. Education increases human capital which enhances the farmer's ability to adopt new agricultural technology which in turn leads to high degree of commercialization. The results of the econometric model indicated that, an increase in the education level of households by one grade increase the probability of farmer's market participation and the expected level of commercialization of maize producing farmers by $2.17 \%$ and 0.01 units, respectively. Moreover, the education level of households increases by one grade the unconditional expected value of maize commercialization increases by 0.01 units. Livestock holding: The marginal effect of this variable revealed that, as the number of livestock increases by one TLU from the mean, the probability of farmer's market participation and the expected level of commercialization of maize producing farmers decreased by $0.97 \%$ and 0.04 units, respectively keeping other variables constant at their mean value. Moreover, as the number of livestock increases by one TLU from the mean, the unconditional expected value of maize commercialization decreases by 0.06 units.

Frequency of extension contact: The marginal effect shows as the smallholder maize producers increase extension contact by one time in a year from the mean, the probability of farmer's market participation and the expected level of commercialization of maize producing farmers decreased by $0.23 \%$ and 0.01 units, respectively keeping other variables constant at their mean value. Moreover, as the smallholder maize producers increase extension contact by one-time in a year from the mean, the unconditional expected value of maize commercialization decreases by 0.01 units.

Training: The marginal effect revealed that smallholder maize producer who got agricultural training had $12.47 \%$ more probability for market participation and 0.05 unit more expected level of maize commercialization compared to those who didn't took training keeping other variables constant at their mean value. Moreover, smallholder maize producers who got agricultural training had 0.08 unit more unconditional expected value of maize commercialization compared to producers who didn't took training.

Off/non-farm income activity: The marginal effect of the model was interpreted as farmers who have got extra income beyond their farm activities. This variable could be interpreted as the farmers engaged in off/nonfarm job, the probability of market participation was $9.42 \%$ and 0.04 unit more expected level of maize commercialization compared to farmers who didn't get any income from off/non-farm income activities keeping all other variables constant at their mean value. Furthermore, farmers who have extra income from off/non-farm income activities beyond their farm activities had 0.06 unit more unconditional expected value of maize commercialization compared their counter parts.

Quantity of maize: The results of the econometric model indicated that, as the quantity of maize production increased by one quintal from the mean, the probability of farmer's market participation and the expected level of commercialization of maize producing farmers could increase by $5.79 \%$ and 0.02 units, respectively keeping other variables constant at their mean value. Furthermore, as the quantity of maize production is increased by one quintal from the mean, the unconditional expected value of maize commercialization increases by 0.03 units.

Lagged price: The results of the econometric model showed that, as lagged price increases by one Ethiopian birr per kilogram of maize from the mean, the probability of farmer's market participation and the expected level of commercialization of maize producing farmers increased by $8.37 \%$ and 0.04 units, respectively keeping other variables constant at their mean value. Furthermore, as lagged price increases by one Ethiopian birr per kilogram of maize from the mean, the unconditional expected value of maize commercialization increases by 0.05 units.

\section{Conclusions of the study}

The overall aims of this study was analysis of maize commercialization among smallholder farmers with a specific objectives of identifying factors determining market participation of smallholder maize producer and investigating the factors affecting the intensity of maize commercialization among smallholder producers. Tobit model was employed to investigate both maize market participation and intensity of participation for smallholder maize producers.

The marginal effect of the Tobit model indicated that education level of household head, attending training, getting income from off/non-farm income activities, quantity of maize produced and lagged price had positive and 
statistically significant influence on both the probability of smallholder maize producers market participation and intensity of market participation. However, total livestock holding and frequency of extension contact were found to have negatively and statistically significant effect on both probabilities of maize producer's market participation and intensity of commercialization. Based on the findings of this study, it is recommended that extension agents should provide practical and professional advices to farmers to enhance their production which in turn increase their probability of maize market participation and intensity of commercialization. In addition, smallholder maize producers who have more number of livestock had less likely to participate in maize marketing and their intensity of commercialization was also low. Therefore, training should be provided for them regarding how to minimize post-harvest loss of their maize storage.

\section{References}

Abafita, J., 1Atkinson, J. and Kim, C.-S. (2016). Smallholder Commercialization in Ethiopia : Market Orientation and Participation. International Food Research Journal, 23(4), 1797- 1807.

Abadi Tefera (2014). Impact of Improved Maize Varieties Adoption On Smallholder Farmers' Marketed Maize Surplus In Oromia Regional State, Ethiopia.

Alemu, D., Gabre-madhin, E., \& Dejene, S. (2006). From Farmer to Market and Market to Farmer : Characterizing Smallholder Commercialization in Ethiopia. Paper Submitted for ESSP 2006 Policy Conference on "Bridging, Balancing, and Scaling up: Advancing the Rural Growth Agenda in Ethiopia" 6-8 June 2006, Addis Ababa, Ethiopia.

Awotide, B. A., Karimov, A. A., \& Diagne, A. (2016). Agricultural technology adoption, commercialization and smallholder rice farmers , welfare in rural Nigeria. Agricultural and Food Economics, 4(3). https://doi.org/10.1186/s40100-016-0047-8

CSA. (2018). The Federal Democratic Republic of Ethiopia Central Statistical Agency. Key Findings of the Agricultural Sample Surveys.

Derso, D., Elemo, E., \& Sawnet, Y. (2016). Determinants of the utilization of agricultural inputs and transfer of agricultural technologies. A review of literature on agricultural extension model. Journal of Agricultural Research and Development, 6(2), 30-33.https://doi.org/http://dx.doi.org/10.18685/EJARD(6)2_EJARD-16010 Review

Doss, C. R., Mwangi, W., Verkuijl, H., \& Groote, H. De. (2003). Adoption of Maize and Wheat Technologies in Eastern Africa : A Synthesis of the Findings of 22 Case Studies. CIMMYT Economic Working Paper 03-06. Mexico,D.F:CIMMYT.

Gebreselassie, S. (2006). Intensification of Smallholder Agriculture in Ethiopia : Options and Scenarios.

Getahun, A. (2020). Smallholder Farmers Agricultural Commercialization in Ethiopia.Agriculture, Forestry and Fisheries, 9(3), 67 74.https://doi.org/10.11648/j.aff.20200903.14

Greene, H.W. 2003. Economic Analysis. New York University, Macmillan Publishing Company, New York. Hagos, A., \& Geta, E. (2016). Review on small holders agriculture commercialization in Ethiopia: What are the driving factors to focused on? Journal of Development and Agricultural Economics Review, 8(4), 65-76. https://doi.org/10.5897/JDAE2016.0718

Hailu, G., Manjur, K., \& Meles, K. (2015). Crop commercialization and smallholder farmers `livelihood in Tigray region, Ethiopia. Journal of Development and Agricultural Economics, 7(03FBD3954989), 314-322. https://doi.org/10.5897/JDAE2015.0649

IFPRI. (2010). Maize Value Chain Potential in Ethiopia. Constraints and Opportunities for Enhancing the System, Working paper.

Kothari, C. R. (2004). Research Methodology: Methods and Techniques, 2ndEdition.New Age International, New Delhi, India.

Legesse, T. A., Tamene, D., Anbessa, B., \& Dereje, G. (2018). Refining Fertilizer Rate Recommendation for Maize Production Systems in Assosa, North Western Ethiopia.

Advanced Techniques in Biology \& Medicine, 6(1), 1-9. https://doi.org/10.4172/2379-1764.1000253 Makombe, G., Namara, R. E., Awulachew, S. B., Hagos, F., Ayana, M., \& Kanjere, M. (2017).

An analysis of the productivity and technical efficiency of smallholder irrigation in Ethiopia, 43(1). Martey, E., Al-hassan, R. M., \& Kuwornu, J. K. M. (2012). Commercialization of smallholder agriculture in Ghana : A Tobit regression analysis, 7(14), 2131-2141 https://doi.org/10.5897/AJAR11.1743

Matthews, N., Deme, S., \& Henning, J. (2015). Analysis of Factors Affecting Technical Efficiency of Smallholder Maize Farmers in Ethiopia. 20th International Farm Management Congress, Laval University, Québec City, Québec, Canada, 2, 44-53.

MoFED (2006). National Accounting Statistics of Ethiopia: The 1998 Ethiopian Fiscal Year (EFY) Update Estimates and Forecasts of the 1999 EFY, 1992 EFY or 19999/2000 base year. National Accounts Department, Ministry of Finance and Economic Development, Addis Ababa.

Moffitt, R., \& Mcdonald, J. F. (1980). The Uses of Tobit Analysis. The Review of Economics and Statistics, 62(2), 
318-321. https://doi.org/10.2307/1924766 National Bank of Ethiopia, A. report. (2018). Ethiopia: Macroeconomic and Social Indicators.

Nigussie, M., D. Tanner, A., \& Twumasi-Afriyie, S. (2001). Enhancing the Contribution of Maize to Food Security in Ethiopia. Proceedings of the Second National Maize Workshop of Ethiopia 12-16 November 2001 Addis Ababa, Ethiopia.

Osmani, A. G., Islam, K., Ghosh, B. C., \& Hossain, E. (2014). Commercialization of smallholder farmers and its welfare outcomes: Evidence from Durgapur Upazila of Rajshahi, 3(6), 119- 126. https://doi.org/10.11648/j.jwer.20140306.16

Senbeta, A. N. (2018). Review on Determinants and Impacts of Smallholder Agricultural Commercialization in Ethiopia. International Journal of Agriculture \& Agribusiness, 1(1), 124-132.

Shita, A., Kumar, N., \& Singh, S. (2018). Agricultural Technology Adoption and its Determinants in Ethiopia: A Reviewed Paper. Asia Pacific Journal of Research, I(LVV), 99-104 